\title{
COSMOLOGÍA AMERINDIA, SHAMANISMO Y ETNOGRAFÍA: UNA CRITICA POSTCOLONIAL
}

PABLO WRIGHT ${ }^{2}$

$U B A$

\begin{abstract}
RESUMEN: Este trabajo revisa algunos supuestos generales de la investigación antropológica sobre shamanismo desde una perspectiva postcolonial. Esta apunta al descentramiento del lugar de enunciación eurocéntrico del sujeto occidental de conocimiento, cuestionando la neutralidad ontológica del lenguaje y la aparente naturalidad de los espacios etnográficos, que permean los métodos de campo de la antropología. Se presenta aquí un análisis de mis investigaciones de campo entre los Qom o Toba del Chaco argentino, evaluando algunos escenarios etnográficos en donde mis preguntas sobre poder shamánico, enfermedad y terapia resultaron tener efectos no intencionales pero negativos en el bienestar de mis interlocutores. Por esta razón, la aplicación de esta perspectiva en la etnografía del shamanismo podría enriquecer la concientización de este proceso intersubjetivo de construcción de conocimiento.
\end{abstract}

PALABRAS CLAVE: Etnografía; shamanismo; modernidad; crítica postcolonial.

ABSTRACT: This paper reviews some general assumptions about the anthropological research on shamanism from a postcolonial approach. The latter aims at decentering the eurocentric locus of enunciation of the Western suject of knowledge, questioning the ontological neutrality of language and the givenness of ethnographic spaces which permeates anthropology's field methods. A personal account of my ethnographic research among the Argentine Chaco Qom (Toba)shamanism is presented, assessing some field scenarios in which my questions about shamanic power, illness and therapy turned out to have unintended but negative effects on my interlocutors' well being. For this reason, applying this perspective on the ethnography of shamanism could improve the epistemological and political awareness of this intersubjective process of knowledge construction.

KEYWORDS: Ethnography; Shamanism; Modernity; Postcolonial critique.

\footnotetext{
1 Versión escrita y reformulada del trabajo presentado en las jornadas (Re) pensando Coletivos Tradicionais na America Latina, organizados por el Programa de Posgraduación en Antropología Social (PPAS), de la Universidad Federal de Rio Grande do Sul, entre el 6 y el 9 de marzo de 2012. Agradezco profundamente al Profesor Sergio Baptista da Silva su invitación a participar en este evento.

${ }_{2}^{2}$ Investigador Principal del Consejo Nacional de Investigaciones Científicas y Técnicas (CONICET); Profesor Titular del Departamento de Antropología, Facultad de Filosofía y Letras (FFyL), Universidad de Buenos Aires; Director de la Sección Etnología del Instituto de Ciencias Antropológicas (FFyL-UBA). ${ }^{2}$ Para una ampliación de estos conceptos, puede consultarse Kusch (1962) y Mignolo (2000) y Wright (2008).
}

Espaço Ameríndio, Porto Alegre, v. 6, n. 1, p. 10-23, jan./jun. 2012. 
PABLO WRIGHT - Cosmología amerindia, shamanismo y etnografia...

\section{Introducción}

La reflexión que aqui presento tiene relación con una crítica del trabajo de campo sobre shamanismo indígena. Analizando cómo es el proceso de construcción del conocimiento antropológico en la academia, cuando uno investiga sobre shamanismo, cosmologías y religiones, se pueden cometer grandes errores con respecto a la gente, a nuestros interlocutores shamanes. Esto sucede cuando, por ejemplo, a éstos les resulta inconveniente conversar con el antropólogo sobre temas sensibles como el poder shamánico. La perspectiva aquí propuesta está alimentada por la llamada crítica postcolonial, o sea, la crítica a la posición eurocéntrica de conocimiento como la única posible que alcance criterios de validez universal, relegando a las restantes usualmente las indígenas en todo el mundo - a gnosis alternativas, periféricas y parcialmente deslegitimadas. Esta crítica aplicada a la antropología supone más que una descontrucción de las retóricas de producción de textos, como lo enfatizara el "turno literario" posmoderno en la disciplina (cf. CLIFFORD y MARCUS, 1986; MARCUS y FISCHER, 1986; CLIFFORD, 1988, por ejemplo), un re-análisis de la construcción de conocimiento antropológico en donde sea central el lugar de enunciación desde donde éste se produce ${ }^{3}$. Esto constituye una verdadera geopolítica del conocimiento, dentro de la cual es muy importante identificar el dónde, el cómo, el cuándo, y el porqué del acceso a determinados saberes sobre el mundo. Esta crítica, desde esta parte del mundo, por otra parte, es más coherente con el sitio que ocupa en la geopolítica mundial, como un locus antiguamente colonial, que a pesar de los cambios con los movimientos de independencia de las metrópolis europeas, y la globalización contemporánea, no sale completamente del colonialismo epistemológico y metodológico disciplinar que nos llega desde el origen histórico de la antropología. Mis reflexiones se detienen brevemente sobre la modernidad, el sujeto universal de la gnosis occidental, y elabora algunos comentarios críticos sobre el papel del sujeto-etnógrafo que se enfrenta con ingenuidad

\footnotetext{
${ }^{3}$ Para una ampliación de estos conceptos, puede consultarse Kusch (1999) y Mignolo (2000) y Wright (2008).
}

Espaço Ameríndio, Porto Alegre, v. 6, n. 1, p. 10-23, jan./jun. 2012. 
PABLO WRIGHT - Cosmología amerindia, shamanismo y etnografia...

epistemológica a sistemas de conocimiento que parten de supuestos diferentes al propio.

I.

Para comenzar, la reflexión que desarrollo está influida por el trabajo del antropólogo brasileño Luiz Eduardo Soares, quien en su remarcable trabajo titulado $A$ invenção do sujeito universal (1995), afirma que la modernidad occidental concibe al sujeto como un individuo cerrado, autónomo, que actúa como una unidad de analisis separada. El sujeto universal, en la empresa científica de conocimiento, es intercambiable si se cumplen con normas metodológicas formales. No hay particularidades en el sujeto universal, y en el trabajo de conocimiento suceden sujetos permutables unos a otros, sin considerar la importancia de las situaciones concretas en donde este sujeto conoce el mundo, y como ellas pueden afectar su estructura ontológica. Este autor critica esa idea de sujeto universal, y la crítica justamente es aportada por la antropología, la que descubre el valor de los conocimientos indígenas y las filosofías no occidentales que presentan, a través de las experiencias de la alteridad cultural - por supuesto definidas desde una visión occidental - otras formas de pensar y practicar la subjetividad, la agencia, y el estatus del conocimiento humano sobre el universo.

Soares (1995) sugiere que la idea del sujeto universal es una invención cultural e histórica de occidente. Sin duda este sujeto cerrado es una ilusión, siendo que lo que existe en realidad, es la intersujetividad, los intersujetos en movimiento y comunicación ${ }^{4}$. Para los antropólogos la instancia paradigmática en donde se produce nuestra desconstrucción como sujetos es la etnografía, lo que puede llevar a un descentramiento existencial de mayor o menor impacto según la situación; una inmersión en los mundos intersubjetivos de nuestros interlocutores. Esto puede representar una experiencia

\footnotetext{
${ }^{4}$ Aquí coincide con la tradición del filósofo Merleau-Ponty y con la obra más reciente del antropólogo Michael Jackson, de Nueva Zelanda, (cf. 1998), que recupera de modo muy creativo la tradición del existencialismo y la fenomenología para una antropología simbólicamente densa de la intersubjetividad.
} 
PABLO WRIGHT - Cosmología amerindia, shamanismo y etnografia...

corporal limítrofe y crítica, donde la dimensión no de un sujeto cerrado sino de la intersubjetividad, se hace carne y palpable, y muchos principios epistemológicos de nuestra formación entran en un proceso de desconstrucción paralelo con el que atraviesa nuestra subjetividad en movimiento hacia el descentramiento.

Por mi propia experiencia de campo, esto puede ocurrir en el trabajo con shamanismo, o con diferentes clases de religiones tanto occidentales como no occidentales - por ejemplo, el espiritismo, la umbanda, o el Santo Daime. Para la visión científica, y el sentido común secular derivado de ésta, las religiones son una ilusión; aunque sabemos, fieles a la herencia durkheimiana y a la tradición antropológica, que ello no es así, que son hechos sociales complejos y polisémicos. En mi trabajo con los Qom o Tobas de la provincia de Formosa (Argentina), sentí que en los diálogos con shamanes con poder, con conversa con los animales, con el viento o a través de los sueños, tomaba contacto con racionalidades diferentes a la científica occidental que me alertaron profundamente sobre el alcance de principios que consideramos casi como parte del orden natural del mundo. Por ejemplo, en el trabajo de campo uno utiliza el lenguaje - la palabra como si solo fuera un instrumento y nada más. La idea moderna de que el lenguaje es neutral y que uno puede hablar de cualquier cosa, en cualquier lugar, en cualquier momento y con quien sea, es puesta bajo una importante sospecha en la etnografía del shamanismo, como ampliaré más adelante. La neutralidad ontológica del lenguaje aquí se transforma en un problema 5 .

La antropología entonces nos muestra, contra la idea hegemónica de la modernidad científica, que los sujetos no son tan intercambiables como se pensaba, ni uno como sujeto-etnógrafo, ni nuestros interlocutores con quienes estamos conversando. Son experiencias históricas únicas, no reversibles ni intercambiables. Si consideramos de este modo los encuentros en el campo, incluyendo esta crítica a la idea del sujeto universal, estaremos mejor preparados para comprender las contingencias culturales, económicas y/o políticas de temas delicados como el poder, la creencia, la salud, la enfermedad, y sus dinámicas

\footnotetext{
${ }^{5}$ Esto aparece magníficamente descripto por Jeanne Favret-Saada (1980) trabajando con brujería en un área rural de Francia; o de Paul Stoller (1989) con hechiceros Songhay, de Niger.
}

Espaço Ameríndio, Porto Alegre, v. 6, n. 1, p. 10-23, jan./jun. 2012. 
PABLO WRIGHT - Cosmología amerindia, shamanismo y etnografia...

intersubjetivas, y para enfrentarnos al estudio etnográfico con una mejor y mayor responsabilidad disciplinar y humana.

Dicho esto, entonces si el sujeto no es intercambiable, el lugar tampoco lo es. Así como el lenguaje, el espacio tampoco es neutral; tanto el sujeto como el espacio se hallan posicionados en alguna parte, y dialécticamente intervinculados. De esta forma, los lugares etnográficos no están dados - a pesar de los famosos mapas de cultural areas que encontramos en los manuales clásicos de antropologia -, sino que son construcciones producidas por las prácticas disciplinares, y por la historia de los encuentros de los antropólogos con sus interlocutores ${ }^{6}$. En esta línea de pensamiento entonces, por ejemplo, no será lo mismo un antropólogo brasileño trabajando en una ciudad brasileña que un colega holandés que viene a Brasil a trabajar allí, ya que en cada caso se pondrán en juego mecanismos diferenciales de la geopolítica del conocimiento. Esto es relevante de tener en consideración porque la tradición antropológica holandesa es diferente de la brasileña, y los sujetos-etnógrafos en la socialización académica e institucional se constituyen de modo diferente. Un rasgo clave, entre otros, se relaciona con las matrices de alteridad 7 que portan cada uno de estos antropólogos: unos, los brasileños generalmente desarrollan investigaciones dentro de su propio país, son ciudadanos de su campo etnográfico, mientras que los otros suelen ir a otros países a investigar, por lo cual son, desde el principio ciudadanos extranjeros trabajando muy lejos de casa. Es la clara distinción histórica que existe entre las llamadas antropología metropolitanas y las periféricas.

Existen análisis críticos sobre la importancia del espacio en la construcción de los lugares etnográficos. Esto se relaciona con una reflexión más general acerca de cómo en occidente se han construido espacios cargados históricamente de sentido utópico, ideal o distópico, según el caso. Una muestra de este proceso, en términos de una geopolítica de la alteridad, es la obra maestra del intelectual palestino Edward Said, Orientalism (1979). En efecto, desde el espacio de la crítica literaria postcolonial, señala cómo occidente construyó discursivamente

\footnotetext{
${ }^{6}$ Para una reflexión sobre la construcción de los espacios etnográficos, se puede consultar Gupta y Ferguson (1997), Clifford (1997) y Wright (2005).

${ }^{7}$ En el sentido que le asignan, por ejemplo Rita Segato (2002) y Claudia Briones (1988) al término.
} 
PABLO WRIGHT - Cosmología amerindia, shamanismo y etnografia...

a oriente, aplicando una perspectiva de análisis muy afín con la antropológica. Este proceso de orientalismo puede compararse, como operación semiótica, semántica y política, con la de los imaginarios nacionales y la delimitación de sus alteridades históricas, sus "otros internos" y sus clases o sectores hegemónicos que se definen como lo civilizado, la norma y lo que es culturalmente aceptable sin hesitación8. En cuanto a los lugares etnográficos, es decir, aquellos espacios que la práctica disciplinar ha transformado en lugares con sentido -pensemos en "la amazonia", "el chaco", "los andes" o "tierras bajas y/o tierras altas" - hay en ellos toda una economía política de la espacialidad, la que actúa en cada uno de nuestros encuentros en el campo. Aunque no la sintamos, allí está presente como una sombra omnipresente que define casi ontológicamente lo que es posible o no de indagar allí.

Asimismo, la geografia crítica ha aportado interesantes ideas sobre la producción social del espacio, las que nos ayudan a entender la arquitectura de los lugares etnográficos. Edward Soja (1989), por ejemplo, retomando a Henri Lefebvre, a la fenomenología y los aportes del existencialismo, reflexiona sobre el papel de las prácticas sociales en la producción de los lugares. De esta forma va más allá de las definiciones apriori de los lugares, los cuales están sujetos a la incesante dinámica de la vida social, y de las prácticas concretas de los actores sociales, lo que él denomina espacialidad existencial. Así entonces, nuestro olhar por los lugares etnográficos será menos ingenuo tanto ontológica como históricamente.

II.

Yendo entonces al caso etnográfico qom, los pueblos indígenas chaqueños, que antiguamente eran cazadores-recolectores, tienen sistemas shamánicos donde el sueño ocupa un lugar importante para el conocimiento del poder y de la realidad; también se relacionan con

\footnotetext{
${ }^{8}$ Autores provenientes de diferentes locaciones geopolíticas han reflexionado críticamente sobre estos tópicos, con quienes es posible dialogar fecundamente, entre otros, Guillermo Bonfil Batalla, Miguel Bartolomé y Alicia Barabas de México; Luiz Eduardo Soares de Brasil, Johannes Fabian de Holanda, Michael Jackson de Nueva Zelanda; Liliana Tamagno y Silvia Citro de Argentina; Talal Asad de EEUU aunque oriundo de Pakistán.
} 
PABLO WRIGHT - Cosmología amerindia, shamanismo y etnografia...

espíritus auxiliares que provienen de lo que occidente entiende como mundo de la naturaleza. En el caso qom, también tienen una influencia muy importante del pentencostalismo norteamericano, producto del cual han surgido desde mediados de la década de 1950 iglesias indígenas en donde hay una síntesis cultural compleja entre esta clase de cristianismo y el shamanismo.

La cosmología qom ha incoporado en su horizonte simbólico figuras y nociones de origen cristiano - v.g., Jesús, la Biblia, consagración, sanación, dones del Espíritu Santo, bendición -, que aluden a entidades muy poderosas y a relaciones entre las personas y aquellas a través de acciones rituales (bendición, consagración, sanación), que son reelaboraciones de acciones rituales shamánicas. Por otro lado, el sistema shamánico sin elementos cristianos, o con muy pocos de ellos, puede encontrarse hoy en día en las comunidades más alejadas de las ciudades, aunque también en las ciudades como Rosario o Buenos Aires, según el lugar de procedencia de los migrantes. En algunos sitios más rurales de Formosa o de la provincia de Chaco se dan estos casos, aunque el discurso del Evangelio qom, como los propios qom denominan este cristianismo indígena y sus iglesias, es hegemónico en toda la región chaqueña, incluyendo otras etnías como los pilagá, los mocoví y los wichí9.

En cuanto a la situación concreta que problematizo aquí, recuerdo que una vez en la comunidad qom La Primavera estaba hablando con un joven Ilamado Alberto que me ayudaba en la traducción de las palabras de su abuelo, José, que era un poderoso pi'ioGonaq (shamán). En esa oportunidad le preguntaba a José a través de su nieto, cuestiones vinculadas con el poder shamánico; es decir, trataba de cubrir el catálogo mínimo de los tópicos básicos del shamanismo: el origen del poder, clases de enfermedades que conocía, formas de terapia, sus nombres en qom y en castellano. Este encuentro fue muy movilizador dado el profundo conocimiento que tenía José sobre la temática. Una vez terminada la entrevista, que fue grabada en su totalidad con anuencia del anciano sabio, nos fuimos a dormir. Al día siguiente volví a hablar con Alberto y me dijo que había soñado con su abuelo José.

\footnotetext{
${ }^{9}$ Para un análisis detallado del surgimiento y características de las iglesias indígenas del Evangelio ver, Miller (1979), Wright (2002) y Ceriani Cernadas y Citro (2005).
} 
PABLO WRIGHT - Cosmología amerindia, shamanismo y etnografia...

Entonces le pregunté si quería contarme algo de ello, y me refirió que en el sueño estábamos hablando ahí y el abuelo le tocaba el hombro. Entonces le pregunté cómo estaba en ese momento y contestó que le había dado un poco de miedo, y que había empezado a pensar que había un problema. Entonces me dijo que creía que no le había gustado a José que habláramos del poder, y tampoco que su nieto estuviera ahí; parecía que la fala era demasiado poderosa para él, que no estaba preparado para escucharla. Esa mañana, Alberto, como consecuencia de esos sucesos - la charla y el sueño - se enfermó.

La segunda escena de campo bajo análisis y crítica nos ubica también en esa colonia junto con un gran shamán llamado Alejandro. Recién lo conocía y se trataba de una persona muy afable y simpática que hablaba abiertamente de su condición de shamán, algo desconocido por mi hasta ese momento; ningún qom había antes reconocido ante mis preguntas etnográficas que fuera shamán, siempre lo eran terceras personas. Alejandro tenía muchos espíritus auxiliares y me contaba con extremo detalle cuáles tenía, dónde estaban y qué relación tenía con cada uno. Su compañero espiritual principal se llamaba nioGonaq, el Silbador, quien estaba a su lado, según él, en todos nuestros diálogos. Yo estaba feliz, ya que encontrar un interlocutor así era como un regalo para el antropólogo, y además no tenía problemas en que grabara nuestros intercambios y tomara fotos. Después de todo un día de entrevistas muy extensas con él, me retiré a la escuela donde me alojaba a unos $2 \mathrm{~km}$ de allí, pensando en volver al día siguiente. En la mañana, retorné a verlo y después de saludarlo, él me preguntó si había dormido bien. Al contestarle que sí, que había dormido sin problemas, me preguntó si no había pasado nada a la noche, a lo cual contesté que no, que nada había pasado. Pero al ver su cara de preocupación le inquirí si había ocurrido algo y entonces contó que le habían robado dos bueyes. Después de manifestar mi pesar por esa situación, Alejandro me repreguntó "pero, no viniste anoche para acá, no estuviste acá?"; "no, no vine acá, estaba durmiendo en la escuela", le contesté. Entonces aclaró lo que había sucedido: la noche atrás Alejandro se había despertado por un ruido, y al salir a ver qué pasaba, vio que estaba el corral de bueyes abierto, y vacío. Había estado toda la noche despierto buscándolos. Mientras hacía su relato, yo pensaba qué relación podría tener eso 
PABLO WRIGHT - Cosmología amerindia, shamanismo y etnografia...

conmigo, lo que se aclaró cuando Alejandro presentó su interpretación de los hechos: que dado que habíamos estado hablando de los seres poderosos paajak ${ }^{10}$, eso no les había gustado y entonces lo habían castigado a él con la pérdida de los bueyes. Ahí entendí el punto de vista de Alejandro, el que manifestaba una diferencia esencial sobre el lenguaje y su poder para actuar sobre el mundo. Para él, hablar de esos seres era igual a llamarlos, a convocarlos, como quien convoca a Dios en la oración cristiana, donde se supone que El está presente. Entonces me di cuenta que ahi había un problema de metodología y de sus consecuencias ontológicas, algo bastante descuidado en la etnografía del shamanismo en general. Para mi hablar, usar el lenguaje, decir palabras era una cosa; para Alejandro era algo muy diferente. Además, él hasta había llegado a pensar que unas huellas de zorro que había visto cerca del corral, que él creía pertenecientes a un ser no humano WaGajaqa'lachigi, asociado con ese animal, y que tiene un comportamiento de trickster, podrían haber sido mías!; es decir, para él eso era posible y por eso construyó esa hipótesis que podía haber esclarecido el robo sufrido. O sea, yo, el antropólogo, transformado en el zorro no humano, había atraido a los bueyes fuera del corral para hacerle una jugarreta a Alejandro, quien había hablado demasiado el día anterior. En su pregunta él dudaba de mi perfil existencial, y yo, ingenuo e ignorante del poder de las palabras, había supuesto que mi interlocutor compartía la misma concepción de neutralidad ontológica del lenguaje de la que yo era un portador bastante poco sutil ${ }^{11}$.

La última escena etnográfica, pero ya no con la lengua oral sino con la palabra escrita, fue protagonizada también por Alejandro cuando ya se había mudado a la comunidad de Misión Tacaaglé, a unos $120 \mathrm{~km}$ al oeste de La Primavera. En ese momento él quería que le escribiera una carta al hospital del pueblo más cercano a la colonia, indicando que él era shamán. De este modo, creía que mi carta podría darle legitmidad frente a los doctores doqshi ("blancos") del hospital para autorizarlo a curar la gente qom que iba allí. Consideraba que muchos qom, además de sufrir enfermedades como tuberculosis o sarampión, también se

\footnotetext{
${ }^{10}$ Paajak es una de las denominaciones qom para referir a los seres no humanos que tienen poder.

${ }^{11}$ Para un análisis más detallado de este caso, ver Wright (1996).
} 
PABLO WRIGHT - Cosmología amerindia, shamanismo y etnografia...

enferman de males que solo ellos conocen, y que para sanarlos lo que necesitaban era un pi'oGonaq.

El pedido de Alejandro me llegó a través de un colega que también trabaja en ese sitio. Después de un tiempo hice la carta, usando el logotipo de la Universidad de Buenos Aires, en donde explicaba quién era Alejandro, su reconocimiento social como shamán, y su deseo de poder ayudar a su gente en una institución médica oficial. Finalmente, la carta llegó a manos de Alejandro, gracias a la ayuda de este colega, y él estaba feliz diciendo "Uh, ahora tengo la credencial para ir al hospital!". La carta era considerada por él como una credencial, un documento que lo podría acreditar como shamán. En mi caso, yo también me sentía bien y útil como antropólogo ya que los estudios académicos sobre shamanismo y cosmología indígenas parecen algo un poco desconectado de las urgencias de la vida cotidiana.

Sin embargo esa felicidad duró poco. La carta creó problemas, ya que desequilibró las relaciones de poder de Alejandro como gran shamán con el pastor qom de la Iglesia Cuadrangular de la colonia, que también era un "gran shamán" pero evangélico; donde su poder derivaba de seres no humanos de origen cristiano.

Lo que sucedió, y que yo ignoraba que estaba pasando en las relaciones políticas intracomunales, es que todo el grupo del pastor, conformado especialmente por su familia extensa, empezó a presionar a Alejandro a través de violencia física y simbólica. Llegaron a tirarle piedras al techo de la casa a la noche para que no durmiera, y empezaron a hablar mal de él. Es decir, se desencadenaron mecanismos de control social cuando hay conflictos de poder y prestigio. Alejandro la pasaba tan mal en su comunidad que decidió irse a otro sitio a vivir, Ilamado Nam Qom, cerca de la ciudad de Formosa, distante $220 \mathrm{~km}$ de Tacaaglé, junto con su hija, para evitar los conflictos con el pastor y su gente.

En un primer momento no entendí lo que pasaba; no tenía clara conciencia de las consecuencias que mi carta había tenido en el delicado equilibrio político de los sistemas de poder de Misión Tacaaglé. Una vez lo vi en su nueva morada y estaba muy desmejorado de salud, había adelgazado sensiblemente, y sufría hipertensión. Al verlo asi, sin saber nada de la situación de conflicto, me explicó lo que le había sucedido. 
PABLO WRIGHT - Cosmología amerindia, shamanismo y etnografia...

Cuando escuché su descripción e interpretación de los eventos, entendí el impacto de la carta en las relaciones interpersonales en la colonia, y me sentí realmente muy mal, con culpa por mi ingenuidad sociológica. Como consecuencia de estos conflictos, Alejandro según los médicos tuvo stress y le dieron de tomar muchas pastillas. Después de un tiempo su salud no se recobró completamente y falleció; tendría entre 75 y 80 años.

Estos episodios me llevaron a reflexionar desde la práctica lo que es un problema filosófico fascinante: el poder de la palabra; la palabra oral y la palabra escrita. La palabra escrita se relaciona más con la racionalidad instrumental de la burocracia estatal, que tiene históricamente una densidad simbólica de legitimidad reconocida en toda el área chaqueña, bajo el nombre de "los papeles". Los papeles refieren a todo aquella carta, documento o certificado necesario para ser reconocido por el estado, ya sea como ciudadano, estudiante, trabajador, empleado oficial, pastor, etc (cf. WRIGHT, 2003). En este contexto socio-histórico, la condición oral de los qom se percibió como una debilidad propia que parcialmente se redimía con documentos de identidad, autorizaciones y cartas de diverso tipo. La carta que escribí entonces adolecía de no haber evaluado con sensibilidad cultural y política su posible impacto como objeto poderoso del mundo doqshi en esa comunidad, y en el estatus socio-político de Alejandro. Esa carta afectó cuestiones de legitimidad de poder local, desnudando la lucha que existía entre dos personajes poderosos, uno de los cuales, el pastor, se sentía atacado en su legitimidad como líder y sanador principal del lugar.

III.

Para concluir, la propuesta de una perspectiva postcolonial en la antropología nos permite comprender mejor la naturaleza epistemológica y teórica de los problemas de producción de conocimiento etnográfico sobre shamanismo, y sus riesgos potenciales para nuestros interlocutores. Mi posición conceptual y metodológica suponía la neutralidad del lenguaje y la posibilidad de interrogar a mis 
PABLO WRIGHT - Cosmología amerindia, shamanismo y etnografia...

interlocutores con una libertad temática que no reconocía el estatus de estos temas dentro de la concepción qom del poder y del lenguaje. Los supuestos que yo ponía en práctica como antropólogo propios de mi socialización en la UBA, se relacionaban con una geopolítica de conocimiento antropológico surgida en países como Francia y los EEUU; es decir, la etnología y su mirada enciclopedista sobre las culturas indígenas del mundo, y la antropología de campo de tradición boasiana, con algunas influencias de la linguística descriptiva. Desde ese lugar de enunciación, me relacioné con Alberto y José, y también con Alejandro y tantos otros interlocutores qom. Sin embargo, los problemas que surgieron de mis preguntas y nuestra conversación sobre el poder, resquebrajaron ese lugar de pregunta y de conceptualización. Así, la perspectiva postcolonial brinda un campo amplio de reflexión y crítica histórica a la mirada eurocéntrica que, en la antropología, aparece naturalizada centralmente en el método, aunque también en los tópicos de interés y en la aparente "naturalidad" de los lugares etnográficos. También en una concepción cerrada del sujeto-etnógrafo poco sensible a la intersubjetividad. En síntesis, la óptica crítica aquí señalada no es la nueva música de la moda antropológica, sino un esfuerzo originado en diversas periferias geopolíticas del mundo desde la década de 1950 desde los movimientos de descolonización en Africa en adelante, orientado a lograr la crítica al lugar de enunciación de occidente, y a generar descentramientos y multiplicidad de esos lugares a lo largo del planeta, sin que la búsqueda de universales sea la imposición de ontologías provinciales o regionales que por la fuerza geopolítica se transforman en hegemónicas. Una mejor formación teórica y práctica de los antropólogos debería incluir estas perspectivas, para poder practicar, al decir de Roberto Cardoso de Oliveira (2004), una mejor escucha, una más atenta mirada, y una escritura antropológica más responsable. De este modo, en los encuentros de campo estaremos mejor preparados para conocer los mundos que se abren a nuestras preguntas antropológicas. El tema del poder shamánico podrá ser, de esta forma, abordado desde una dimensión tanto filosófica como políticamente más auténtica y responsable en este diálogo de saberes, de tiempos y de espacios culturales que es la empresa antropológica. 
PABLO WRIGHT - Cosmología amerindia, shamanismo y etnografia...

\section{Bibliografía citada}

BRIONES, Claudia. La alteridad del "Cuarto Mundo": una deconstrucción antropológica de la diferencia. Buenos Aires: Ediciones del Sol, 1988.

CARDOSO DE OLIVEIRA, Roberto. El trabajo del antropólogo: mirar, escuchar, escribir. Avá Revista de Antropología, Posadas, n. 5, p. 55-68, 2004.

CERIANI CERNADAS, César; CITRO, Silvia. El Movimiento del Evangelio entre los Toba del Chaco argentino: na revisión histórica y etnográfica. In: GUERRERO JIMÉNEZ, Bernardo (Org.). De Indio a Hermano: pentecostalismo indígena en América Latina. Iquique: Ediciones Campvs, 2005. p. 111-170.

CLIFFORD, James. The predicament of culture: Twentieth-Century ethnography, literature, and art. Cambridge/ Massachussets/London: Harvard University Press, 1988.

Spatial practices: fieldwork, travel, and the disciplining of Anthropology. In: GUPTA, Akhil; FERGUSON, James. Anthropological locations: boundaries and grounds of a field science. Berkeley/Los Angeles/London: University of California Press, 1997. p. 185-222.

CLIFFORD, James; MARCUS, George (Org.). Writing culture: the poetics and politics of ethnography. Berkeley: University of California Press,1986.

FAVRET-SAADA, Jeanne. Deadly words: witchcraft in the Bocage. Cambridge: Cambridge University Press, 1980.

GUPTA, Akhil; FERGUSON, James. Discipline and practice: "The Field" as site, method, and location in Anthropology. In: GUPTA, Akhil; FERGUSON, James (Orgs.). Anthropological locations: boundaries and grounds of a field science. Berkeley/Los Angeles/London: University of California Press, 1997. p. 1-46.

JACKSON, Michael. Minima ethnographica: intersubjectivity and the Anthropological Project. Chicago/London: The University of Chicago Press, 1998.

KUSCH, Rodolfo. América profunda. Buenos Aires: Biblos, 1999.

MARCUS, George; FISCHER, Michael M. J. Anthropology as cultural critique: an experimental moment in the Human Sciences. Chicago/London: The University of Chicago Press, 1986.

MIGNOLO, Walter D. Local histories/global designs. coloniality, subaltern knowledges, and border thinking. Princeton: Princeton University Press, 2000.

MILLER, Elmer S. Los tobas argentinos. armonía y disonancia en una sociedad. México: Siglo XXI eds., 1979. 
PABLO WRIGHT - Cosmología amerindia, shamanismo y etnografia...

SAID, Edward. Orientalism. New York: Vintage Books, 1979.

SEGATO, Rita L. Identidades políticas y alteridades históricas: una crítica a las certezas del pluralismo global. Runa, Buenos Aires, n. 23, p. 239-275, 2002.

SOARES, Luiz Eduardo. A invenção do sujeito universal. Campinas: Editora da Unicamp, 1995.

SOJA, Edward. Postmodern geographies: the reassertion of space in critical social theory. London/New York: Verso, 1989.

STOLLER, Paul. The taste of ethnographic things: the senses in Anthropology. Philadelphia: University of Pennsylvania Press, 1989.

WRIGHT, Pablo. Crónicas de un encuentro shamánico: Alejandro, el "Silbador", y el Antropólogo. In: LAGARRIGA; Isabel; GALINIER, Jacques; PERRIN, Michel (Orgs.). Chamanismo en Latinoamérica: una revisión conceptual. México: Plaza y Valdés, 1996. p. 167-186.

L'Evangelio: pentecôtisme indigène dans le Chaco argentin. Social Compass, New York, v. 49, n. 1, p. 43-66, 2002.

Colonización del espacio, la palabra y el cuerpo en el Chaco argentino. Horizontes Antropológicos, Porto Alegre, v. 19, p. 137-152, 2003.

Cuerpos y espacios plurales: sobre la razón espacial de la práctica antropológica. Indiana, Berlim, v. 22, p. 55-74, 2005.

"Ser-en-el-sueño": crónicas de historia y vida toba. Buenos Aires: Editorial Biblos-Culturalia, 2008.

Espaço Ameríndio, Porto Alegre, v. 6, n. 1, p. 10-23, jan./jun. 2012. 